\title{
A Perceptual Theory of Hope
}

\author{
MICHAEL MILONA \\ Auburn University \\ KATIE STOCKDALE ${ }^{1}$ \\ Sam Houston State University
}

\begin{abstract}
This paper addresses the question of what the attitude of hope consists in. We argue that shortcomings in recent theories of hope have methodological roots in that they proceed with little regard for the rich body of literature on the emotions. Taking insights from work in the philosophy of emotions, we argue that hope involves a kind of normative perception. We then develop a strategy for determining the content of this perception, arguing that hope is a perception of practical reasons. Our proposal stands in contrast with familiar views on which hope is fundamentally about the good. We conclude by considering the increasingly popular idea that some hopes are non-intentional and thus, by implication, non-perceptual. We reply by arguing that our perceptual theory plausibly generalizes to these instances of hope.
\end{abstract}

Keywords: hope, perception, emotion, moral psychology

\section{Introduction}

The view that hope involves a desire for $p$ and a belief that $p^{\prime}$ s obtaining is possible but not certain has become known as the standard or orthodox account of hope (Martin 2014; Meirav 2009). Some philosophers think that the standard view is sufficient to capture some of our trivial hopes, like the hope that the sun will come out soon (Calhoun in press; Pettit 2004). There is widespread consensus in the literature, however, that the standard account cannot make sense of our most significant hopes, like the hope to be cured of cancer or the hope that a wrongdoer be brought to justice. An increasing number of philosophers have tackled the question of what, exactly, these more significant hopes consists in

1. This paper is the product of full and equal collaboration between authors.

Contact: Michael Milona <milonamc@gmail.com> and Katie Stockdale <katiestockdale@shsu.edu>? 
(e.g., Martin 2014; Pettit 2004). Despite these efforts, we believe that an adequate account has yet to be offered.

This paper re-examines the issue in a new way. We argue that the shortcomings of recent theories have methodological roots, namely that many of the most detailed treatments of hope tend to proceed with little regard for the rich body of literature on the emotions. By attending carefully to how hope patterns similarly to emotions, we will better understand the nature of hope. In particular, a familiar debate in the philosophy of emotions about the phenomenon of emotional recalcitrance carries over to debates about the nature of hope. We argue that hope can be recalcitrant, and that cases of recalcitrant hope pose a problem for what is arguably the most well-worked out theory of hope: Adrienne M. Martin's incorporation analysis of hope. In light of the problems with Martin's theory, but inspired by her insight that hope involves some kind of normative assessment, we offer a perceptual theory of hope. At a first pass, our proposal is that hope is a normative perception, specifically one as of the hoper's practical reasons.

The perceptual theory of hope is not simply another analysis of hope, but plausibly has distinctive epistemological significance. In normative epistemology, many philosophers attempt to demystify how we learn what we ought to do by arguing that normative beliefs are justified by non-doxastic, perceptuallike states with normative content (see Huemer 2005; Oddie 2005). One of the biggest challenges for this approach is to say precisely what these non-doxastic states are (see Mackie 1977: 38). If the perceptual theory of hope is correct, then hope becomes part of an attractive answer to this challenge. This paper thus takes a fresh approach to the "What is hope?" question, and ultimately arrives at a novel theory that raises intriguing possibilities about the role of hope in normative inquiry.

\section{Toward a New Approach to Hope}

We often see the word 'hope' alongside 'optimism,' 'pessimism,' and 'despair.' Philosophers tend to agree that when we are optimistic that $p$, we are confident that $p$ will occur. It makes sense, for example, to say, "I not only hope that $p$; I am actually pretty optimistic about $p$ !" where the expression of optimism reveals a greater level of confidence that $p$ will obtain than the hope. It is also possible to be pessimistic that $p$, but still hope that $p$. It makes sense to say "you know, I am pretty pessimistic that $p$ but I do still have some hope that $p$ will occur." Despair, in contrast, is at odds with hope. We cannot both despair of an outcome and hope that it will obtain. We take these distinctions between hope, optimism, pessimism, and despair for granted, focusing on the nature of hope as an attitude 
that is compatible with pessimism, embodies less confidence than optimism, and is inconsistent with despair.

Virtually everyone agrees that hope involves at least the desire for an outcome and the belief that the outcome is possible but not certain (Day 1969; Downie 1963; Wheatley 1958). ${ }^{2}$ But recent scholars have argued that this standard account does not quite capture the nature of hope. Although we do not have space to canvass all attempts to revise the standard belief-desire account, we mention some that seem to us to be among the most promising. ${ }^{3}$ Luc Bovens (1999), for instance, maintains that hope involves conscious thoughts, or 'mental imaging,' about the desired outcome. The idea is that we only count as hoping if we at least intermittently devote mental energy to thoughts about what it would be like if the desired outcome were to occur.

Other theorists maintain that the standard account does capture some of our trivial hopes, but that our most important hopes - hopes in which we are significantly invested, and those we sustain in the face of barriers to success - involve more than belief and desire (Martin 2014; Pettit 2004). Martin offers an example that she calls Cancer Research to illuminate an example of these more significant hopes. The example centers on two hypothetical patients, Alan and Bess, both of whom suffer from terminal cancer and have exhausted standard treatment options. Alan and Bess enroll in an early-phase clinical trial of an experimental drug; they know that there is a less than one percent chance that they will receive medical benefit from the drug, and they share a strong desire to find a miracle cure. Alan notes that, while he hopes the drug will turn out to be a miracle cure, he has enrolled in the trial primarily to benefit future patients due to the unlikelihood of his hope being realized. Bess, on the other hand, appeals to her hope that she will be the one percent as "what keeps her going," and notes that she has enrolled in the trial primarily because of this possibility (Martin 2014: 14-15). Martin argues that Bess but not Alan can be described as "hoping against hope": her hope for a miracle cure is strong despite the odds against her. Bess's hope is stronger than Alan's even though both patients assign the same probability estimate to the miracle cure and their desires for a miracle cure are equally strong.

This case is meant to show that, to account for the fact that Alan's and Bess's shared hopes differ in strength, there must be some additional feature of hope beyond belief and desire. Given Bovens's mental imaging theory, we might think that the differences in hoping are traceable to differences in the patients' conscious thoughts about the desired outcome. But Martin contends that Alan

2. It is possible to hope for an outcome that is in the past, such as when one hopes that one's friend performed well in her interview hours after the interview occurred. The key is that the hopeful agent must be uncertain about whether something has, or will, obtain.

3. For a critical discussion of other theories not discussed here, see Martin (2014). 
and Bess may engage in similar mental imaging yet the differences in hope remain. She finds equally inadequate Philip Pettit's (2004) view of substantial hope as cognitive resolve. According to Pettit, substantial hope involves acting as if the desired outcome will come about, or at least as if it were likely to come about. But if hope involves a kind of cognitive resolve whereby the hopeful person acts as if the desired outcome will obtain, then in hoping, Bess would say something like, "I grant you the chance is only one in a thousand, but don't think about that!" (Martin 2014: 22). Martin points out that this description does not cohere with cancer patients' actual experiences of hope in these cases. ${ }^{4}$ Instead, patients like Bess who hope for a miracle tend to say things like, "I grant you the chance is only one in a thousand, but it is possible!" (Martin 2014: 21). So it is not that hopeful patients resolve to act as if the drug will be a miracle cure, but that they tend to "hope for the best, plan for the worst" (Martin 2014: 22).

Martin defends what she calls the incorporation analysis of hope in an attempt to accommodate attractive features of both Bovens's and Pettit's views, while resolving the difficulties noted above. She points out that that certain activities are characteristically hopeful. Thinking, imagining, and acting in accordance with one's desire are hopeful activities in which people engage, among other hopeful activities including fantasizing, planning, intending, and feeling in certain ways directed toward the desired outcome. Martin argues that these hopeful activities are not necessary and sufficient conditions, but constitutive features of hope as a syndrome. For example, hoping might involve fantasizing about and imagining the fulfillment of our desire (i.e., engaging in hopeful thoughts) as well as anticipating its fulfillment. Martin describes anticipation as a kind of positive feeling about the outcome's obtaining, a feeling that is captured by thoughts such as "wouldn't it be wonderful if . .." (2014: 33). On the other hand, when we despair (i.e., when we are not at all hopeful), we experience gloomy feelings that lead to thoughts like, "how unfortunate ... the world is so hard . . . etc." (Martin 2014: 33).

Martin observes that a syndrome analysis runs the risk of being ad hoc, allowing for any and all mental activities to count as part of hope. So she argues there must be some element of hope that unifies the activities constitutive of hope as a syndrome, knitting them together as features of hope and not just a random collection of things. Martin argues that the unifying element of hope is 'incorporation.' More specifically, in hope, we incorporate our desire for an outcome into our rational scheme of ends, judging that there are sufficient reasons to engage in thoughts, feelings, activities, and modes of perception directed toward the fulfillment of one's desire. In other words, hope involves taking the probability

4. The Cancer Research case comes from Martin's encounters with real patient-participants in clinical trials during her postdoctoral fellowship at the National Institute of Health. 
(however small) of the hoped-for outcome's being realized as nevertheless possible, and as licensing the agent (on grounds of practical reason) to treat her desire for the hoped-for outcome, and the outcome's desirable features, as reasons for engaging in the hopeful activities of thinking, imagining, fantasizing, and so on. What is missing from the belief-desire account of hope is the idea that "one stands ready to offer a certain kind of justificatory rationale for ... forms of planning, thought, and feeling" (Martin 2014: 35). Thus, on Martin's view, "to hope for an outcome is to desire (be attracted to) it, to assign a probability somewhere between $o$ and 1 to it, and to judge that there are sufficient reasons to engage in certain feelings and activities directed toward it" (2014: 8).

All of these analyses of hope have done much to deepen our understanding of the phenomenon. But we maintain that there are important shortcomings with each. In particular, the debate about the nature of hope within analytic philosophy suffers from a methodological shortcoming. The problem is that much of this work has taken place without regard for the rich literature on the philosophy of emotions. This is somewhat surprising, given that many philosophers interested in questions about the value of hope class hope with other emotions. Margaret Urban Walker, for example, suggests that hope is an 'emotional stance' composed of desire and belief, as well as forms of attention, thoughts, and feelings (2006: 48). Victoria McGeer similarly characterizes hope as a 'complex dynamic' involving attitude, emotion, activity, and disposition (2004: 101). Alan Mittleman (2009) argues that hope is an emotion in his Hope in a Democratic Age, then proceeds to defend hope as a civic virtue throughout the book. Interestingly, many philosophers writing in the philosophy of emotions use the example of hope in illustrating their views, and treat it as an emotion without question (D'Arms \& Jacobson 2000; de Sousa 1987; Deigh 2004; Goldie 2004; Gordon 1987; Nussbaum 2004; Roberts 2003).

Martin (2014: 24 Footnote 27) explicitly notes that she wishes to tackle hope on its own terms, rather than as an emotion, for the nature of emotions is a vexed question and it's not obvious that there is a single, true account of the emotions to be had. Crucially, however, one needn't come down on the question of whether hope is an emotion in order to benefit from insights in the philosophy of emotions. This is because the preceding analyses - especially Martin's ownillustrate that hope is at least similar to paradigm emotions in many key respects. We illustrate in Sections 3 and 4 how philosophers' understanding of hope can be substantially improved by drawing out some of the similarities between hope and paradigm emotions. 


\section{Recalcitrance}

Martin's incorporation analysis of hope hits on an important truth, namely that hope involves a kind of normative assessment. But we argue that she mischaracterizes the nature of this assessment, thereby distorting our understanding of hope. The best way to see this is to notice that Martin's error is analogous that made by so-called judgmentalists about emotion.

Let's begin by observing a similarity between the incorporation analysis of hope and judgmentalist theories of emotion. On the incorporation theory, hope involves judging that one has sufficient reasons to engage in hopeful activities, standing ready to offer a justificatory rationale for doing so (see Martin 2014: 8). This is a strong form of endorsement: those who hope in the fullest sense believe that their hope is justified. Similarly, judgmentalist theories of the emotions claim that emotions involve not only affect or feeling, but also a characteristic evaluative judgment. For example, Philippa Foot proposes a judgmentalist theory of pride according to which feeling pride requires that one believe that the object of pride is "in some way splendid and in some way one's own" (1978: 76). The similarity between the incorporation analysis of hope and judgmentalist theories of emotion is that the normative assessment involved is a kind of judgment.

Philosophers of the emotions now widely reject traditional judgmentalist theories because they struggle to account for the phenomenon of recalcitrant emotions (see D'arms \& Jacobson 2003; Greenspan 1988; Roberts 1988). ${ }^{5}$ Recalcitrant emotions are those which persist despite a conflicting judgment. To take a familiar example, a person who is afraid of flying on a plane despite judging that flying is safe experiences recalcitrant fear. The worry for the judgmentalist is that, for any evaluative judgment that is supposed to be constitutive of the emotion, the agent can apparently experience the emotion while holding the contrary judgment. Of course, a judgmentalist could insist that recalcitrant emotions always involve an agent maintaining contradictory beliefs. But this isn't an attractive move, for the beliefs would often be transparently contradictory. For

5. Some philosophers continue to characterize their views as 'judgmentalist' including, for instance, Robert Solomon and Martha Nussbaum. But both philosophers have a capacious understanding of what counts as a judgment, one which does not obviously contrast with perception. Nussbaum, for instance, is explicit that she uses 'perception' and 'judgment' interchangeably to refer to the normative assessment involved in emotions, and she says that both are a kind of feeling (2001: 60). Solomon speaks of "judgments of the body," which are, unlike many ordinary judgments, affect-laden and also often nonpropositional and prelinguistic (2003: 191). In a personal correspondence with Robert C. Roberts, Solomon apparently wrote that what Roberts calls 'perceptual construal' is precisely what he means when he argues that emotions are judgments (Roberts 2014: 15). Thus what we argue here does not contrast with views such as Solomon's and Nussbaum's, as may first appear, although we do believe that the language they use (in terms of judgment rather than perception) can lead to confusion. 
example, an agent who experiences recalcitrant fear of flying would judge both the flying on a plane is dangerous and also judge that it is not. As Justin D'arms and Daniel Jacobson point out, in most such cases, this maneuver will involve a "dubious attribution of peculiarly conflicted beliefs" (2003: 129).

If hope, like other emotions, can be recalcitrant, then Martin's incorporation analysis will not be able to account for such cases. Agents with recalcitrant hopes would not treat their desire and desirable features of the hoped-for outcome as justification for engaging in hopeful activities, as Martin's view requires. We believe that hope can be recalcitrant, and examples are readily available in the literature. Bovens describes a case in which a person who goes to a car race finds himself fantasizing about the possibility of a spectacular accident and feels motivated to sit near the part of the track at which an accident is most likely to occur (1999: 679). He hopes for an accident, but is also deeply ashamed that he has the hope. The agent's shame signifies that he does not judge himself to have sufficient reasons to engage in hopeful activities such as imagining and fantasizing about the accident, even though he finds himself hoping for an accident. Similar examples are not hard to come by. A person might find themselves strongly hoping to get back together with an abusive ex-partner, yet judge that they are not at all justified in their hope-that getting back together with their abusive ex-partner would be a terrible thing to do. ${ }^{6}$

In cases of recalcitrant hope, the hoper does not judge that she has sufficient reasons to engage in hopeful activities, nor does she stand ready to offer justification of the sort that the incorporation analysis requires. Of course, Martin might say that this isn't a problem, since hope in the fullest sense requires incorporation. Similarly, a judgmentalist about fear might say that fear in the fullest sense requires endorsement at the level of judgment, even if there is some weaker sense of fear that requires no such endorsement. But it is no accident, we think, that judgmentalists about emotions have never taken this track, for cases of recalcitrant emotions are ubiquitous - and it is unclear why a theory of the emotions would exclude such cases as only quasi-emotions, or as not emotions in the fullest sense. As we shall explain momentarily, the strategy of setting aside recalcitrant emotions can also appear especially ad hoc in the face of other ways of characterizing the sense in which emotions involve a normative assessment.

6. One might wonder whether the person really desires to get back together with the abusive ex after all. But it is perfectly conceivable that one might strongly desire and so hope for such an outcome while at the same time judging that doing so would be a terrible thing. This state of affairs makes sense of people who find themselves naturally drawn to reconnect with her ex-partners, imagining what they are up to, and longing for their presence, yet who at the same time criticize themselves for engaging in such activities. The presence of such hopes thus helps to explain why people sometimes end up scheduling psychotherapy sessions for assistance in eliminating desires they know they ought not to have. 


\section{The Perceptual Model(s)}

In the face of the problem of recalcitrant emotions, we might be inclined to give up on the idea that hope involves any normative assessment at all. And there are theories of the emotions that one might lean on as a model (e.g., Whiting 2009). But we agree with Martin that in the Cancer Research case there is a difference in the way that each patient assesses the situation, and that this difference is a function of how they hope. The task in this section is to characterize the nature of the normative assessment involved, once again taking our cue from work in the philosophy of the emotions.

Philosophers drawn to the view that emotions involve a normative assessment, but who recognize the possibility of recalcitrant emotions, typically lean on an analogy with perception. Just as a person can perceive that a stick in water is bent even while believing that it is not bent, so too a person can emotionally experience the world as being some way even while believing or judging it to not be that way. So, for example, fear might be thought to involve a perceptuallike experience of the object of fear as dangerous, and anger an experience of having been wronged or of a situation as unfair. The list of philosophers moved by the phenomenon of emotional recalcitrance to the view that emotions are perceptual-like states includes Peter Goldie (2000), Robert C. Roberts (2003), Sabine Döring (2003), Jesse Prinz (2007), and Christine Tappolet (2016), among many others.

Our idea is that hope involves a perceptual-like normative assessment. We do not make the claim that hope involves a literal perception, although some philosophers of the emotions do treat emotions as literal perceptions (Prinz 2007). We only commit to the weaker claim that hope involves a non-doxastic normative representation. There are different ways to think about the normative perception involved in hope. Our favored conception begins with Peter Goldie's view of emotions, according to which the perceptual component of an emotion is revealed by careful reflection on emotional feelings. As Goldie explains, "when an emotion is directed toward its object, then this is a sort of feeling toward the object" (2004: 96). The relevant feeling is not a bodily feeling (although it may accompany bodily feelings) like the feeling of one's heart pounding or the feeling of sweaty palms. Rather, it is an emotional feeling, a feeling that is directed toward an object in the world "beyond the bounds of our bodies," a feeling that is bound up with how we take in the world of experience (Goldie 2000: 48). When we experience fear, for instance, an accurate description of what we feel will make reference to some object experienced as dangerous.

A natural supplement to a 'feeling toward' perceptual model takes its cue from work in the philosophy of perception and helps to clarify the specific kind of non-doxastic experience we have in mind (Bengson 2015; Chudnoff 2012; Pry- 
or 2000). Philosophers of perception point out that perception has presentational phenomenology, to borrow a term from Elijah Chudnoff (2012). The idea that in perceptually experiencing the world, the perceiver is presented with things as being a certain way. Beliefs, in contrast, lack presentational phenomenology, for in believing the agent takes a stance on what is true. Thus we are not interested in any kind of non-doxastic experience, but more specifically a non-doxastic experience as of something being presented to the experiencer as true. Incidentally, presentational phenomenology is often taken to be a central part of the explanation of why perception is able to justify beliefs (see Chudnoff 2012: 64). Thus presentational phenomenology bears on an observation with which we started, namely that hope's perceptual dimension may be important for normative epistemology, though we limit our focus here to the moral psychology of hope.

These ideas about 'feeling towards' and presentational phenomenology carry over to hope in an illuminating way. Hope has a phenomenology, a "what it is like" to be in a state of hope, at least if we agree with Bovens that hope cannot be entirely unconscious. And like other emotions, part of what it is like to hope is to experience some kind of feeling. In our view, an accurate description of the feelings involved in hope will make reference to a normative way in which the world appears to the agent. And, moreover, we take this representation to have presentational phenomenology: reality presents itself to the person hoping as containing the relevant normative properties. This helps us to understand the sense in which Bess is taking a different normative stance on her situation than Alan in Cancer Research without locating that difference at the level of judgment or belief. But what exactly is this normative perception of? We characterize it in more detail below, but at a first pass, the idea is that in hoping we see the desired outcome that is possible but not certain as encouraging. In our view, then, hope is an attitude that involves:

1. The desire for an outcome.

2. The belief that the outcome's obtaining is possible but not certain.

3. Seeing the possible-but-uncertain desired outcome as encouraging to varying degrees.

4. Hopeful feelings.

A proponent of the incorporation analysis may object that, in giving up the element of incorporation, we have lost what unifies the constitutive features of hope as a syndrome. But the perceptual theory unifies these elements in an elegant way. On our view, hopeful feelings are a perception of the possible-butnot-certain desired outcome as encouraging. No element of hope floats entirely free of the others.

The perceptual model may mark a surprising return to the standard account 
of hope according to which hope involves only a desire that $p$ and belief that $p$ is possible but not certain. Whether it does depends on one's view of desire. A traditional view of desire is that desires are perceptual-like experiences of the good or, alternatively, of reasons (Oddie 2005; Scanlon 1998; Stampe 1987; Tenenbaum 2007). On this view, desires do more than simply motivate behavior; they also have a characteristic phenomenology. As Graham Oddie puts it, "when I desire that $\mathrm{P}, \mathrm{P}$ has a certain magnetic appeal for me. It presents itself to me as something needing to be pursued, or promoted, or embraced" (2005: 41). Given this view about desire, both the desiderative and perceptual components of hope are naturally taken to be identified with the feeling component of hope. The belief component, then, is part of the (causal) explanation for why the agent sees the outcome (by way of the desire/perception/feeling) as encouraging: because of the belief that it is possible though uncertain (see Milona in press).

We do not want to insist on a perceptual view of desire, so we leave it as an open question whether hope involves a sui generis hopeful perception or whether the normative perception involved in hope is reducible to desiderative normative perceptions. Either way, the perceptual theory has the advantages of Martin's, Bovens's, and Pettit's views without the corresponding flaws. First, it accounts for the normative assessment involved in hope (as Martin's view does), while still allowing for the phenomenon of recalcitrant hope. Second, it captures Bovens's idea that hope cannot be unconscious, for perceptual-like experiences cannot be unconscious. But we go further in saying that a hoper must also perceive the content of the relevant images (in light of the probability assignment) as encouraging. Finally, the perceptual view makes sense of Pettit's insight that hopers are especially sensitive to the prospect that the desired outcome might occur, for the probability assignment is part of what they perceive as encouraging. But our account does not require hopeful agents to act as if the probability of the outcome were higher than it is.

At this point, we need to clarify some points about our argument. The first is that we do not insist that our perceptual theory of hope (modeled in large part on Goldie's theory of the emotions) is the uniquely best perceptual theory of hope - we haven't the space to argue for this here. Other perceptualist views are possible. Prinz (2007), for instance, maintains that emotions involve nondoxastic normative representations, but unlike our favored approach, he does not hold that an accurate phenomenological description of emotional feelings will make reference to normative properties or relations. It is rather that the best story of what it means for a mental state to represent some content generates this result. Mark Schroeder (2007: 146-163) defends a broadly similar view about desire according to which desiderative feelings come to have normative content by a process analogous to the way that visual perceptions come to have their contents; but he does not claim that it is part of the nature of desid- 
erative feelings that they have such content. One may, then, attempt to model an alternative perceptual theory of hope on Prinz's approach to emotions or on Schroeder's approach to desires. We suspect such an account would have virtues similar to ours. ${ }^{7}$

By now, some readers may be itching to point out that perceptual theories of emotions are controversial, and thus we can expect a perceptual theory of hope to be equally so. But notice, first, that we are starting from Martin's insight that some kind of normative assessment is implicated in hope; and we believe that the possibility of recalcitrant hope illustrates that this evaluation is best captured by a perceptualist rather than judgmentalist model. Furthermore, a key point often lost in the literature is that many objections to perceptual theories of the emotions are not attacks on the psychological framework of those theories. Michael Brady (2013), for instance, argues that emotions are not like perceptions because, while emotions can be irrational, perceptions cannot be. He uses this observation as part of an argument for the conclusion that perceptions, but not emotions, provide us with reasons to believe that their content is true. But notice that Brady's aim is to draw an epistemological disanology between emotions and perceptions. He leaves the psychological analogy between emotions and perceptions intact, and indeed it plays an important role in his positive view about the value of emotions. ${ }^{8}$

\section{The Content of Perception}

If hope involves a normative perception, then it is fair to ask what the content of that assessment is. Thus far, we have suggested that in hoping we perceive the possibility that the desired outcome will obtain as encouraging. While we

7. In the emotions literature, there is also an important distinction between views that maintain emotions have normative content and those which locate the normative dimension of emotions outside the content (see Deonna \& Teroni 2012). A similar issue arises in the literature on desire (see Schafer 2013). We do not explore this complex debate here, but we note that we have no qualms with those who prefer to locate the normative assessment of hope outside the content of the attitude.

8. Bennett Helm (2015) argues that the phenomenon of emotional recalcitrance tells against a psychological analogy between emotions and perceptions. On his view, recalcitrant emotions are often irrational, in contrast with recalcitrant perceptions which are never irrational. Yet, crucially in this context, recalcitrant emotions are never irrational in the manner of a judgment. Emotional construals are a sui generis kind of representation, importantly different from both judgments and perceptions. One concern about Helm's argument is that is highly questionable whether emotions can ever, strictly speaking, be (ir)rational (see Michael Milona 2016: 903; see also Barry Maguire 2017 for an argument that there are no reasons for affective attitudes). But even if Helm's argument works, it does not provide a framework for vindicating Martin's incorporation theory of hope. It would rather lead to a theory located somewhere between Martin's view and our own perceptualist model. 
think this description captures the phenomenology of hope, it is a metaphor, one which it would be desirable to unpack. This might seem a futile task, however, since perceptualists about emotions notoriously struggle to adjudicate between different proposals for what sort of normative assessments are involved in emotions. For example, does fear involve a representation of its object as fearsome, as dangerous, or as something else?9 D'arms and Jacobson (2003: 134) point out that it's not clear how we would begin to adjudicate these different theories. They also think that the difficulty of doing so calls the perceptualist's psychological framework into question, for if emotions are normative perceptions then it must be true that they have certain normative contents. Similarly, perceptualists about desire have struggled to say whether desires represent the good, practical reasons, or something else. ${ }^{10}$ In this section, we propose an account of the content of the normative perception involved in hope.

Among those who think that hope involves a normative assessment, it is popular to claim that hope assesses its object as good. Historically prominent proponents of this view include Augustine (2008: 36) and Aquinas (2007: 760), while more recent advocates include Robert C. Roberts (2007), Charles Pinches (2014), and potentially Jonathan Lear (2006: 103). Depending on how the idea is developed, this thesis might be taken to mean that hope represents its object as good simpliciter, or, alternatively, that it represents it as good for the hoper. By contrast, as we have seen, Martin develops a picture on which hope represents the hoper's practical reasons. In particular, in hoping that $p$ we take desirable features of $p$ and the possibility of $p$ as sufficient reasons for engaging in hopeful activities. In what follows, we suggest a general strategy for adjudicating these different hypotheses.

The strategy relies on our judgments about when attitudes are fitting. Fitting emotions, as we conceive of them, are those which accurately represent whatever normative property they are hypothesized to be about. This is a common view among those who believe that emotions involve normative assessments (Döring 2003; Greenspan 1988; Prinz 2007; Roberts 2003; Solomon 1976; Tappolet 2016). For example, if a joke is funny, and if laughter represents the property of being funny, then it is fitting to laugh at the joke. The fact that a joke is immoral may be a reason not to laugh, but its immorality does not necessarily change the view that laughter is fitting (cf. D'arms \& Jacobson 2000). Our proposal is that, given a perceptual model of hope, a hypothesis about what hope is a perception of (goodness, reasons) should align with judgments about when hope is fitting. In other words, a fitting hope should also be an accurate perception.

9. On the difference between being fearsome and being dangerous, see Francois Schroeter (2006).

10. Alex Gregory (2013) as well as Michael Milona and Mark Schroeder (2017) have recently argued in favor of the view that desires represent practical reasons rather than goodness. 
In determining whether the fittingness of hope aligns with a given hypothesis about what sort of normative assessment is involved in hope, we should keep in mind more than simply whether the relevant normative property or relation is present. To borrow a metaphor from D'arms and Jacobson, determining the fittingness of an emotion consists in considering both the shape and size of the attitude (2000: 73). An emotion's shape is fitting if the object really does have the evaluative features the emotion represents it as having. But emotions, including hope, might be overblown or experienced too strongly; when this happens, the emotion is not fitting in terms of its size (an important dimension of the overall fittingness of the emotion). For example, on the view that hope represents its object as good, a hope that dinner is tasty plausibly has the right shape, for it is good if dinner comes out tasty. But if the affective intensity of the hope were overwhelming, then it would not have the right size, since it is not that significant that dinner tastes great.

In our view, the hypothesis that hope involves perceptions of the good faces serious problems. Return to Martin's example of Cancer Research. In that case, Bess strongly hopes that she be cured of cancer in the face of a one percent chance of a cure. It may initially seem as though the view that hope involves a perception of its object as good makes sense of this case. After all, it would be very good if Bess were to be cured. But we believe that appearances are misleading, and trouble emerges when we notice the relevance of the low probability that the hope will be realized to whether the hope is fitting. Martin stipulates that Bess's hope is based in an accurate estimate that she has a one percent chance of being cured. But we might still doubt whether, given such low odds, it really is fitting for Bess to have such a strong hope to be cured. She might, instead, more fruitfully devote her mental energies elsewhere to make the most of the time she has left. Even if we grant that Bess's hope in the face of a one percent chance is fitting, Bess's hope would not be fitting if the chance of being cured were a trillion to one. Yet this would not make the object of her hope-that she is cured-any less good. In sum, the fact that Bess's hope is far overblown in strength given the probability that her hope will be realized renders her hope unfitting overall, despite the fact that the shape of her hope is correct.

The observation here is a simple one: whether an instance of hope is fitting fluctuates with the probability that the hoped-for outcome will be realized. But how good the outcome is does not similarly fluctuate. ${ }^{11}$ The same goes for a view on which hope represents its object as good for the hoper. How good the realiza-

11. See Milona and Schroeder (2017) on the view that desires involve perceptions of the good. They argue that such a view leads to systematic inaccurate representations of the good in competitive contexts (e.g., a desire to win a race), and that this systematic inaccuracy tells against the hypothesis that desires involve representations of the good. We believe that our observations about hope and probability may extend to desire, providing further support for Milona and Schroeder's 
tion of the hope would be does not typically fluctuate with how likely the outcome is. Intensely hoping, for example, that all forms of social oppression will be eliminated in one's lifetime aims at an outcome the obtaining of which would be extremely good (in general, for the hoper, and for millions of people around the world); but such a hope is not fitting, since it represents the possibility that oppression will end in one's lifetime as far more encouraging than it is. The view that, in hoping, we assess the object of hope as good-a view which traces back to Augustine and Aquinas-appears dubious in light of these considerations.

In our view, it is more plausible that hope represents practical reasons. This view squares more easily with the idea that the fittingness of a hope is sensitive to the likelihood of the outcome's obtaining. While the goodness of an outcome may not fluctuate with how likely the outcome is, our reasons to attempt to bring an outcome about certainly do. For example, the weight of Bess's reasons to seek a cure through the experimental drug trial increase as it becomes more likely that the trial will be successful, and decrease as it becomes less likely. ${ }^{12}$ The view that hope involves a normative perception of reasons fits well with the metaphorical idea with which we started, namely that in hoping we see the desired outcome that is possible but not certain as encouraging. In hoping for a miracle cure, Bess perceives certain facts about what it would be like to be cured-for example, that she would be able to spend more time with her grandchildren - as reasons to seek a cure; and they appear to her as reasons in part because of her representation of the chance she might actually be cured. Borrowing terminology from Jonathan Dancy (2004: 41-42), we might say that the probability assigned to a desired outcome often functions to intensify or attenuate our apparent reasons to pursue it, making the reasons appear more or less weighty. ${ }^{13}$ We thus agree with Martin about the content of the normative assessment involved in hope-as one of practical reasons-but disagree about the nature of the normative assessment. In perceiving that one has practical reasons to pursue an end, one does not necessarily judge that one is justified in doing so. ${ }^{14}$

case. Similarly, their observations about desire may extend to hope; but we do not have space to explore these connections here.

12. Bess may perceive other reasons to participate in the trial that are independent of her hope to be cured through her participation. She might, for instance, recognize the same reasons to participate in the trial as Alan did-namely, to benefit future patients. (The perception of these reasons may even be grounded in a distinct hope to benefit others through her participation.)

13. According to an alternative model, the probabilities become part of complex reasons (cf. Dancy 2004: 38-43). It doesn't matter for our purposes how one chooses to characterize the phenomena.

14. One may wonder how our proposal characterizes hopes for outcomes the agent does not see any way to promote. In our view, there is no one-size-fits-all answer; it depends on the details of the case at hand (including potentially controversial background judgments about which reasons are in fact present in a given case, if any, as well as the weight of those reasons). In some instances, a hoping agent may see considerations as reasons but also recognize those reasons as 


\section{Conclusion: A Complete Theory of Hope?}

We have defended a perceptual theory of hope according to which hope involves: (i) a desire that $p$, (ii) a belief that $p$ is possible-but-not-certain, (iii) perceptuallike experiences of reasons to pursue $p$, and (iv) an emotional feeling of hopefulness. We remain non-committal about how these different components relate. On our favored approach, an adequate description of what it is like to experience hopeful feelings makes reference to the normative way in which reality is presented to the hoper. One might also take up the view that desires are a kind of normative perception, in which case one might conclude that the standard belief-desire account of hope is true, after all. But precisely how one comes down on how these components of hope relate to one another will depend on how one understands affective phenomenology and desire, and we do not settle these issues here.

Before closing, we will address one last question about hope: Does the perceptual model fail to capture an important class of hopes? Philosophers have tended to focus on intentional hopes, or hopes that are for some outcome to obtain. But sometimes, we talk of 'having hope' and 'being hopeless' more generally. Matthew Ratcliffe (2013) and Cheshire Calhoun (in press) have recently argued that there is a form of pre-intentional hope that is a precondition for intentional hopes. If there is such a thing as pre-intentional hope, then it might not fit into the perceptual model, for perceptions are always about something. Calhoun describes pre-intentional hope, or what she calls 'basal hope' in the following way:

Basal hopefulness is not hope for this or that outcome, but is what Matthew Ratcliffe describes as a non-propositional, pre-intentional sense of the future - "a kind of general orientation or sense of how things are with the world"15 or an "experiential backdrop"16 on which particular hopes for this or that become intelligible. (In press)

One response to Calhoun's notion of basal hope is to set it aside, insisting that our aim is to analyze intentional hopes. But we believe that the perceptual model,

defeated by a lack of control (e.g., a hope oriented to the past). In other cases, an agent may be unsure how to act on the reasons that they see themselves as having, or they may see reasons to cultivate virtuous patterns of thought and feeling that will ready them for concrete action should an opportunity arise (e.g., a hope that Trump lose the 2020 election). Other cases may be exercises of empathetic hoping whereby the hoper sees reasons that are possessed by another agent.

15. Matthew Ratcliffe (2013: 602).

16. Ratcliffe (2013: 600). For additional discussion of pre-intentional states that involve an affectively laden mode of anticipating the future, see also Matthew Ratcliffe, Mark Ruddell, and Benedict Smith (2014). 
as well as some recent work in philosophy of mind, points toward an alternative understanding of the (important) phenomenon that Ratcliffe's and Calhoun's accounts reference.

At first glance, basal hopefulness appears to be something like a mood, in contrast with hopes that $p$, which are more like emotions. It is occasionally said that moods such as elation, irritation, and anxiety are not about anything, though they often give rise to emotions such as joy and anger which do have intentionality. A general feeling of irritation, for instance, seems to involve a distinctive 'raw feel,' but according to some, the feeling does not seem to be about anything in particular (Deonna \& Teroni 2012: 4). But the view that moods are wholly nonintentional is now widely doubted, and for good reason (Crane 1998; Goldie 2000: 143-151; Kind 2013; Mendelovici 2013). For example, a number of philosophers have described many of our moods, including euphoria, depression, and melancholy, "as being directed at both nothing and everything" (see Kind 2013: 120). ${ }^{17}$ This suggests that we are right to deny that our moods, at least many of them, have particular objects. Yet it seems wrong to conclude that they have no object whatsoever. A tempting solution is to treat the relevant moods as aimed at the entire world (Baier 1990: 3; Lyons 1980: 104). Here is how Robert Solomon expresses the idea:

Europhoria, melancholy, and depression are not about anything in particular (though some particular incident might well set them off); they are about the whole of our world, or indiscriminately about anything that comes our way, casting happy glows or somber shadows on every object and incident of our experience. (1976: 173; quoted in Kind 2013: 120)

We do not insist that all moods take the entire world as their object, but we think that something along these lines fits well with how Ratcliffe and Calhoun talk about basal hope. Calhoun argues that basal hopefulness involves taking an interest in the future generally or globally, rather than hoping for the fulfillment of specified desires. Basal hope is what agents lose when they become depressed; they are not depressed about some particular thing, but "about the future generally. They lose a globally motivating interest in The Future" (in press).

Whereas Calhoun and Ratcliffe understand basal hope as pre-intentional, we suggest that basal hope is intentional but highly general-its aboutness is directed toward a highly general state of affairs. Basal hope, we think, is similar to Robert Solomon's understanding of happiness as a meta-emotion. Solomon

17. Amy Kind identifies a number of philosophers who make this observation, including Peter Goldie (2000: 18), Laura Sizer (2000: 747), Ronald de Sousa (2014). 
argues that the meta-emotion of happiness is "an ongoing summary evaluative judgment about our being in the world. It is a kind of all-embracing emotion, one that is not just about any particular aspect of our lives but about our lives as a whole" (2007: 265). Basal hope seems similar; it involves a perception that one has practical reasons to continue on living one's life, and following one's desires. Although there may be many seemingly plausible ways of trying to describe basal hope as an intentional state (cf. Ratcliffe 2013: 603), we believe our proposal is especially attractive insofar as it leads to a unified picture of hope, treating basal hope as continuous with paradigmatic intentional hopes.

A perceptual theory of hope, according to which hope involves a perception of practical reasons, makes hope an attractive candidate for contributing to agents' ethical outlooks. Our ambition is to have paved the way for investigations into hope's role in guiding practical inquiry.

\section{Acknowledgements}

We would like to thank the John Templeton Foundation for funding this research, and our fellow scholars in the Hope $\mathcal{E}$ Optimism: Conceptual and Empirical Investigations Project for lively discussions throughout the 2016-2017 academic year that helped to inspire our writing. In this regard, we would like to especially thank Luc Bovens, Andrew Chignell, Alex Esposito, and Nicole Hassoun. We also benefitted significantly from discussions with Hannah Tierney. Katie would like to thank Cheshire Calhoun, Chike Jeffers, Greg Scherkoske, Susan Sherwin, and Lisa Tessman for feedback on ideas related to this paper. Michael would like to thank Mark Schroeder for many valuable discussions about desire over the years that would eventually help him to theorize hope. Finally, we would like to thank Ergo's editors and two anonymous referees for helping us strengthen our argument.

\section{References}

Aquinas, Thomas (2007). Summa Theologica: Volume II-Part II, First Section (Fathers of the English Dominican Province, Trans.). Cosimo Classics.

Augustine of Hippo (2008). Enchiridion on Faith, Hope and Love (Bruce Harbert, Trans.). New City Press.

Baier, Annette (1990). What Emotions Are About. Philosophical Perspectives, 4, 1-29. https://doi.org/10.2307/2214185

Bengson, John (2015). The Intellectual Given. Mind 124(495), 707-760. https://doi. org/10.1093/mind/fzv029

Bovens, Luc (1999). The Value of Hope. Philosophy and Phenomenological Research, 59(3), 667-681. https://doi.org/10.2307/2653787 
Brady, Michael (2013). Emotional Insight: The Epistemic Role of Emotional Experience. Oxford University Press. https://doi.org/10.1093/acprof:oso/9780199685523.001.0001

Calhoun, Cheshire (in press). Motivating Hope. Doing Valuable Time: The Present, The Future, and Meaningful Living. Oxford University Press.

Chudnoff, Elijah (2012). Presentational Phenomenology. In Sofia Miguens and Gerhard Preyer (Eds.), Consciousness and Subjectivity (51-72). Ontos Verlag. https://doi. org/10.1515/9783110325843.51

Crane, Tim (1998). Intentionality as the Mark of the Mental. In Anthony O'Hear (Ed.), Contemporary Issues in the Philosophy of Mind (228-251). Cambridge University Press. https://doi.org/10.1017/CBO9780511563744.013

D'Arms, Justin and Daniel Jacobson (2000). The Moralistic Fallacy: On the Appropriateness of Emotions. Ethics, 61(1), 65-90. https://doi.org/10.2307/2653403

D'Arms, Justin and Daniel Jacobson (2003). The Significance of Recalcitrant Emotion (or, Anti-Quasijudgmentalism). In Anthony Hatzimoysis (Ed.) Philosophy and the Emotions (127-145). Cambridge University Press. https://doi.org/10.1017/ CBO9780511550270.009

Dancy, Jonathan (2004). Ethics without Principles. Oxford University Press. https://doi. org/10.1093/0199270023.001.0001

Day, J. P. (1969). Hope. American Philosophical Quarterly, 6(2), 89-102.

de Sousa, Ronald (1987). The Rationality of Emotion. MIT Press.

de Sousa, Ronald (2014). Emotion. In Edward Zalta (Ed.), Stanford Encyclopedia of Philosophy (Spring 2014 Edition). Retrieved from https://plato.stanford.edu/archives/ spr2014/entries/emotion/

Deigh, John (2004). Primitive Emotions. In Robert C. Solomon (Ed.), Thinking about Feeling: Contemporary Philosophers on Emotions (9-27). Oxford University Press.

Deonna, Julien and Fabrice Teroni (2012). The Emotions: A Philosophical Introduction. Routledge.

Döring, Sabine (2003). Explaining Action by Emotion. Philosophical Quarterly, 53(211): 214-23o. https://doi.org/10.1111/1467-9213.00307

Downie, R. S. (1963). Hope. Philosophy and Phenomenological Research, 24(2), 248-251. https://doi.org/10.2307/2104466

Foot, Philippa (1978). Hume on Moral Judgment. In Virtues and Vices and Other Essays in Moral Philosophy (74-80). University of California Press.

Goldie, Peter (2000). The Emotions: A Philosophical Exploration. Oxford University Press.

Goldie, Peter (2004). Emotion, Feeling, and Knowledge of the World. In Robert C. Solomon (Ed.), Thinking about Feeling: Contemporary Philosophers on Emotions (91-106). Oxford University Press.

Gordon, Robert (1987). The Structure of Emotions: Investigations in Cognitive Philosophy. Cambridge University Press.

Greenspan, Patricia (1988). Emotions and Reasons. Routledge.

Gregory, Alex (2013). The Guise of Reasons. American Philosophical Quarterly, 51(1), 6372.

Helm, Bennett (2015). Emotions and Recalcitrance: Reevaluating the Perceptual Model. Dialectica, 69(3), 417-433. https://doi.org/10.1111/1746-8361.12119

Huemer, Michael (2005). Ethical Intuitionism. Palgrave Macmillan.

Kind, Amy (2013). The Case against Representationalism about Moods. In Uriah Kriegel (Ed.), Current Controversies in the Philosophy of Mind (113-134). Routledge. 
Lear, Jonathan (2006). Radical Hope: Ethics in the Face of Cultural Devastation. Harvard University Press.

Lyons, William (1980). Emotion. Cambridge University Press.

Mackie, John (1977). Ethics: Inventing Right and Wrong. Penguin.

Maguire, Barry (2017). There Are No Reasons for Affective Attitudes. Mind. Advance online publication. https://doi.org/10.1093/mind/fzx011

Martin, Adrienne M. (2014). How We Hope: A Moral Psychology. Princeton University Press.

McGeer, Victoria. The Art of Good Hope. Annals of the American Academy of Political and Social Science, 592(1), 100-127.

Meirav, Ariel (2009). The Nature of Hope. Ratio, 22(2), 216-233. https://doi.org/10.1111/ j.1467-9329.2009.00427.x

Mendelovici, Angeli (2013). Intentionalism about Moods. Thought, 2(2), 126-136. https:// doi.org/10.1002/tht3.81

Milona, Michael (2016). Taking the Perceptual Analogy Seriously. Ethical Theory and Moral Practice, 19(4), 897-915. https://doi.org/10.1007/s10677-016-9716-7

Milona, Michael (in press). Finding Hope. Canadian Journal of Philosophy.

Milona, Michael and Mark Schroeder (2017). Desiring Under the Proper Guise. Manuscript submitted for publication.

Mittleman, Alan (2009). Hope in a Democratic Age. Oxford University Press.

Nussbaum, Martha (2001). Upheavals of Thought: The Intelligence of Emotions. Oxford University Press.

Nussbaum, Martha (2004). Emotions as Judgments of Value and Importance. In Robert C. Solomon (Ed.), Thinking about Feeling: Contemporary Philosophers on Emotions (183199). Oxford University Press.

Oddie, Graham (2005). Value, Reality, and Desire. Oxford University Press.

Pettit, Philip (2004). Hope and Its Place in Mind. Annals of the American Academy of Political and Social Science, 592(1), 152-165.

Pinches, Charles (2014). On Hope. In Kevin Timpe and Craig Boyd (Eds.), Virtues and Their Vices (349-368). Oxford University Press.

Prinz, Jesse (2007). The Emotional Construction of Morals. Oxford University Press.

Pryor, James (2000). TheSkeptic and the Dogmatist. Noûs, 34(4), 517-549. doi:10.1111/00294624.00277

Ratcliffe, Matthew (2013). What Is It to Lose Hope? Phenomenology and the Cognitive Sciences, 12(4), 597-614. https://doi.org/10.1007/s11097-011-9215-1

Ratcliffe, Matthew, Mark Ruddell, and Benedict Smith (2014). What Is a "Sense of Foreshortened Future?" A Phenomenological Study of Trust, Trauma, and Time. Frontiers in Psychology, 5, 1026.

Roberts, Robert (1988). What an Emotion Is: A Sketch. Philosophical Review, 97(2), 183209. https://doi.org/10.2307/2185261

Roberts, Robert (2003). Emotions: An Essay in Aid of Moral Psychology. Cambridge University Press.

Roberts, Robert (2007). Spiritual Emotions: A Psychology of Christian Virtues. Wm. B. Eerdmans Publishing.

Roberts, Robert (2014). Justice as an Emotion Disposition. In John Deigh (Ed.) On Emotions: Philosophical Essays (14-28). Oxford University Press.

Scanlon, T. M. (1998) What We Owe Each Other. Harvard University Press. 
Schafer, Karl (2013). Perception and the Rational Force of Desire. Journal of Philosophy, 110(5), 258-281. https://doi.org/10.5840/jphil2013110528

Schroeder, Mark (2007). Slaves of the Passions. Oxford University Press.

Schroeter, Francois (2006). The Limits of Sentimentalism. Ethics, 116(2), 337-361. https:// doi.org/10.1086/498463

Sizer, Laura (2000). Towards a Computational Theory of Mood. British Journal for the Philosophy of Science, 51, 743-769. https://doi.org/10.1093/bjps/51.4.743

Solomon, Robert (1976). The Passions. Anchor Press/Doubleday.

Solomon, Robert (2003). Not Passion's Slave: Emotions and Choice. Oxford University Press.

Solomon, Robert (2007). True to Our Feelings: What Our Emotions Are Really Telling Us. Oxford University Press.

Stampe, Dennis (1987). The Authority of Desire. Philosophical Review, 96(3), 335-381. https://doi.org/10.2307/2185225

Tappolet, Christine (2016). Emotions, Value, and Agency. Oxford University Press.

Tenenbaum, Sergio (2007). Appearances of the Good: An Essay on the Nature of Practical Reason. Cambridge University Press.

Walker, Margaret Urban (2006). Moral Repair: Reconstructing Moral Relations after Wrongdoing. Cambridge University Press.

Wheatley, J. M. O. (1958). Wishing and Hoping. Analysis, 18(6), 121-131. https://doi. org/10.1093/analys/18.6.121

Whiting, Demian (2009). The Feeling Theory of Emotions and the Object-Directed Emotions. European Journal of Philosophy, 19(2), 281-303. https://doi.org/10.1111/j.14680378.2009.00384.x 